\section{A survey analysis program for small computers}

\section{GARY NARKAUS and RALPH DIPPNER State University of New York State College of Optometry \\ 100 East 24th Street, New York, New York 10010}

This program (GARY1.BA) was designed for use on all types of surveys requiring tabulation of raw data. The basic function of the program is to count the occurrences of specific pieces of information contained within the records of the data, where each record represents one questionnaire, one patient, etc. For example, suppose one wished to determine the frequency of occurrence of pathology with respect to sex. By inputting needed information, the program prints in a cross-tabulation the number of females with pathology $A$, the number of females with pathology B, etc., and the number of males with pathology $A$, the number of males with pathology $B$, etc.

The program allows for up to two selections to eliminate certain records from the count. (In the above example, one may wish to tabulate pathology by sex for only those individuals over 65 years of age.) The program also allows for grouping some of the data, for example, age of the individuals, say, 0-19 years as Group 1, 20-39 years as Group 2, etc. Besides a record count, the program can output percentages of the counts, including percentages across, down, and of the grand total count.

Sample runs are included in this paper to demonstrate the use of the program.

The Data. All data are created on one file and stored on tape prior to running the program. The data consist of a series of records where each patient questionnaire represents one record. Each record contains a fixed number of fields, where each field represents one piece of information about that individual (e.g., age, sex, etc.). Each field can be encoded using any letters or numbers. No more than four characters are allowed in any one field.

The data may be in one of two forms: One uses a delimiter; the other form does not. With a delimiter, each field is separated by a unique character (e.g., a comma or a space) and up to three lines of data per record are allowed. When no delimiter is used, the data is in one continuous line and only one line per record is allowed. Since there is no separation between fields, the first run of the program requires that the end of each field be specified. (The procedure is explained later under Field Specification File.)

The maximum number of fields allowed per record is limited by the number of lines of data per record (i.e., one or three, depending on the form of the data) and by BASIC, which restricts a single line of input to 72 characters. If longer fields are used, there wiil be fewer fields available for use.

With the existing program and one DECtape, and data that may need editing, the reasonable maximum on the data file is 90,000 characters. Thus, for a data file consisting of 45 characters per record, a maximum of 2,000 records may be input.

Files. Under most circumstances, one to several files must be created and stored upon the first run of the program. Subsequent runs require only that the names of the previously created files be input. Possible files include field specification, group specification, and report header files. An automated field input file may be created, but this must be done prior to running the program.

Field Specification File. This file is only necessary when the data has no field separation indicator (delimiter), as in the case for both sample runs shown in Figures 1 and 2. A request for "field specs" is the first statement printed upon running the program. If the fields are separated by an indicator, the character to be used as a delimiter is input, for example, a comma or a space. Of course, the delimiter character must be unique, that is, it cannot be contained in the regular data. If the field specifications were created and stored on a previous run, the name that was given to that file is entered (see Figure 2); otherwise, the carriage return is pressed to proceed to the creation of the field specifications. Figure 1 provides an example of how the field specifications are input.

Group Specification File. If any fields are to be further summarized prior to tabulation, a "group" specification file must be created. Only fields with numeric characters may be grouped, and a maximum of six fields may be grouped in any one run. Creation of a group specification file is demonstrated in Figure 1, where Field 3 (age) has been divided into four groups of ages 0-64, 65-74, 75-84, 85-99 years.

Report Header File. This option was added to the program to clarify the output tables. Without this option, the table count is preceded by a line indicating the two field numbers which were cross-tabulated. Using this option allows field names to be printed in addition to the field numbers. Each field name is limited to nine characters in length; headers are not allowed if there are over 75 fields. Figure 1 provides an example for creation of a report header file.

Automated Field Input File. The automated field and selection input option is an extremely useful feature. Without this option, after each table print the user must input the next two fields to be tabulated and the selections, if any. So frequent user intervention is required. The automated input feature allows the user to input a large number of fields and their correspond- 
Figure 1. Data file creation and a sample run showing: (1) creation of needed files and (2) the record search feature.

R TECO
*EWDATA1\$
I001ABRA68FA
002ALLE76MB
003BARR83MA
004CARS72FAB
005JONE65MC
006LARS88MB
007MART92FBC
008MORR62FA
009SILV65FC
010WATT80MAB
\$\$

*EX\$\$

R BASIC

NEW OR OLD-OLD GARY1

READY

RUNNH

ENTER NAME OF FIELD SPECS (PRESS RETURN IF NEW SPECS),

OR ENTER DATA SEPARATION INDICATOR

? (Carriage return pressed by user)

ENTER \# LINES OF DATA PER RECORD

$? 1$

ENTER ENDING COLUMN \#'S FOR EACH FIELD, USE 99 FOR

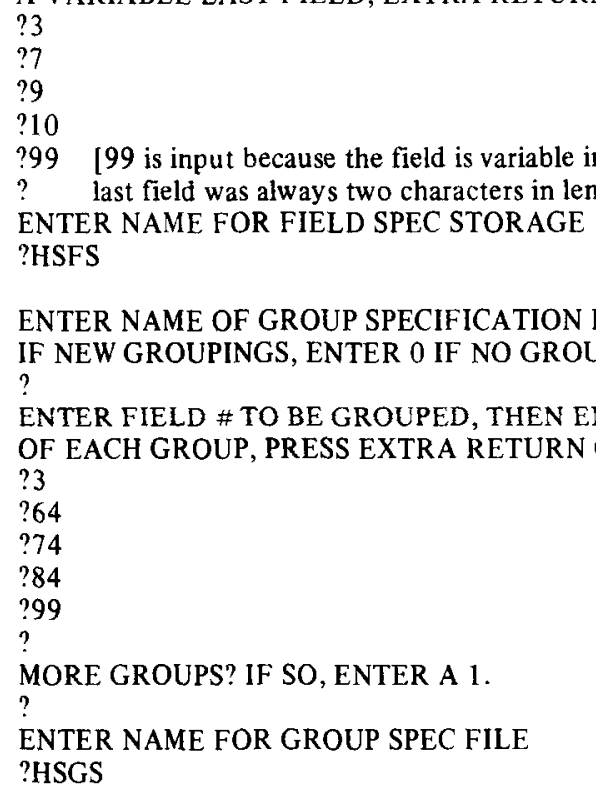

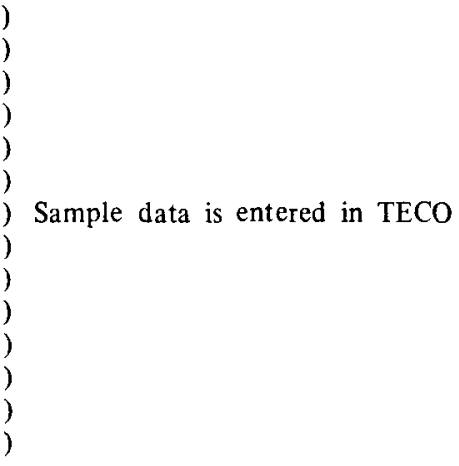

First request by Teletype is for field specs, in this case a field spec file by the name of HSFS is created.

)

)

) Group specs are created. Field 3

) (see data) is grouped as follows:

$0-64,65-74,75-84$, and 85-99.

)

)

)

)

)

)

)

)

)

Report header file is created.

)

)

)

)

)

) No automation on this run. 
ENTER DATA FILE NAME

?DATA1

WHAT FIELDS AND \%'S? USE THE FORM X,Y,P

$? 3,5,0$ (User inputs fields to be tabulated; no \% in this case)

SELECTION IF ANY, PRESS RETURN IF NO SELECTION

? (Carriage return pressed. No selection in this case.)

3 by 5

AGE BY PATHOLOGY

RECORD COUNT

$\begin{array}{lll} & \text { AB } & \text { A } \\ 1 & 0 & 1 \\ 2 & 1 & 1 \\ 3 & 1 & 1 \\ 4 & 0 & 0 \\ & 2 & 3\end{array}$

) Data file created above is obtained

WHAT FIELDS AND \%'S? USE THE FORM X,Y,P

?3,5,0 (User inputs next fields, but they will not be used since a detail select and printout will be done.)

SELECTION IF ANY, PRESS RETURN IF NO SELECTION

?D05EQC (User tells computer to search through all records in the data file and print all records which contain a " $\mathrm{C}$ " in Field 5.) ANOTHER SELECTION IF ANY, PRESS RETURN IF NO SELECTION?

005JONE65MC

009SILV65FC

WHAT FIELDS AND \%'S? USE THE FORM X,Y,P

? ("CTRL" and "C" buttons pressed simultaneously to terminate program run.)
Teletype prints records as re) quested.

Figure 2. Automated input file creation and a sample run demonstrating its use.

R TECO
${ }^{*}$ EWBATCH $\$$
$\mathbf{1 4 , 5 , 3}$
$3,5,0$
$04 \mathrm{EQM}$
$\$ \$$
${ }^{*} \mathrm{EX} \$ \$$

.R BASIC

NEW OR OLD-OLD GARY1

READY

RUNNH

ENTER NAME OF FIELD SPECS (PRESS RETURN IF NEW SPECS), OR ENTER DATA SEPARATION INDICATOR

?HSFS

ENTER \# LINES OF DATA PER RECORD

$? 1$

ENTER NAME OF GROUP SPECIFICATION FILE, PRESS RETURN

IF NEW GROUPINGS, ENTER 0 IF NO GROUPINGS

?HSGS

ENTER HEADER FILE NAME, PRESS RETURN TO CREATE NEW HEADERS,

ENTER ZERO FOR NO HEADERS

?HSRH

ENTER NAME OF AUTOMATED FIELD INPUT FILE, PRESS RETURN

IF NO AUTOMATION DESIRED

?BATCH

ENTER DATA FILE NAME

?DATA1

WHAT FIELDS AND \%'S? USE THE FORM X,Y,P

(Report header file created in first run is recalled.)

(Automated field input file is obtained.)

$4,5,3$

SELECTION IF ANY, PRESS RETURN IF NO SELECTION
) Sample automated field and selec) tion input file is created in TECO.

) (Normally a very large number ) of fields and selections would ) be input.)

)
[Field spec file created in first run (Figure 1) is recalled.]

(Group spec file created in first run is recalled.)

t by user is performed.) 
4 BY 5

SEX BY PATHOLOGY

\begin{tabular}{ccccccl}
\multicolumn{2}{l}{ RECORD COUNT } & & & & \\
& AB & A & BC & B & C & TOTAL \\
F & 1 & 2 & 1 & 0 & 1 & 5 \\
M & 1 & 1 & 0 & 2 & 1 & 5 \\
& 2 & 3 & 1 & 2 & 2 & 10
\end{tabular}

\begin{tabular}{lllllll}
\multicolumn{2}{c}{ \% } & ACROSS & & & & \\
& AB & A & BC & B & C & ROW \%S \\
F & 20 & 40 & 20 & 0 & 20 & 50 \\
M & 20 & 20 & 0 & 40 & 20 & 50
\end{tabular}

\% DOWN

$\begin{array}{lrllll} & \mathrm{AB} & \mathrm{A} & \mathrm{BC} & \mathrm{B} & \mathrm{C} \\ \mathrm{F} & 50 & 67 & 100 & 0 & 50 \\ \mathrm{M} & 50 & 33 & 0 & 100 & 50 \\ \mathrm{COL} \% \mathrm{~S} 20 & 30 & 10 & 20 & 20\end{array}$

WHAT FIELDS AND \%'S? USE THE FORM X,Y,P

$3,5,0$

SELECTION IF ANY, PRESS RETURN IF NO SELECTION

04EQM

ANOTHER SELECTION IF ANY, PRESS RETURN IF NO SELECTION

3 BY 5

AGE BY PATHOLOGY

\begin{tabular}{cccccl}
\multicolumn{2}{c}{ RECORD COUNT } & & & \\
& AB & A & B & C & TOTAL \\
2 & 0 & 0 & 0 & 1 & 1 \\
3 & 1 & 1 & 1 & 0 & 3 \\
4 & 0 & 0 & 1 & 0 & 1 \\
& 1 & 1 & 2 & 1 & 5
\end{tabular}

WHAT FIELDS AND \%'S? USE THE FORM X,Y,P

RE AT LINE 00610

RE AT LINE 00610

END OF PRINT

READY

ing selections prior to running the program. Having then been created as a file, the computer is able to read the various fields and selections as needed.

Creation of this file is accomplished by using the TECO utility program ${ }^{1}$ and can be done by the inexperienced user with the knowledge of only a few TECO commands (see Figure 2).

Field and Percentage Input. After all field, group, and report header files have been created or read, a request is made to input the two fields which are to be crosstabulated, along with the percentage tables desired, if any. As shown in Figure 1, this information is input in the form $X, Y, P$ where $X$ and $Y$ represent the two fields to be tabulated and $P$ is the percentage code. When $\mathbf{P}=0$ no percentages are output and only the record count table is printed. When $P=1$ percentages across rows are output in addition to the record count. When $\mathrm{P}=2$ percentages down columns are printed. When $\mathrm{P}=3$ both percentages (across and down) are printed in addition to the record count. Figure 1 shows an input of Fields 3 and 5 for cross-tabulation, with no percentages.

After the record count table and percentage tables, if any, have been printed by the Teletype, control of the program returns to the field input (see Figure 1 or 2), and the next two fields to be cross-tabulated along with the percentage code are entered by the user.

When inputting the fields, the number of codes within each of the requested fields must not exceed the maximum table size of a 34 by 20 matrix. That is, the $\mathrm{X}$ field cannot have more than 34 different codes within that field, and the $Y$ field cannot have more than 20 different codes. If either limit is exceeded, the execution of the program terminates at that point. These restraints can be altered by very minor reprogramming. Merely change the dimension statement to 68 by 10 , for example, if a large $\mathrm{X}$ field is needed.

Selection Option. Immediately following each request 
for field and percentage input, a request is made for a "selection," if any. This selection option allows the elimination of certain records from the count. For example, an investigator may want a tabulation of age by pathology for males only.

Selection input must be in the form XXYYZZ, where $\mathrm{XX}$ is the field to be selected, $\mathrm{YY}$ is the selection function [i.e., equal (EQ), not equal (NE), less than (LT), or greater than (GT)], and $\mathrm{ZZ}$ is a specific code within that field. The field number selected $(\mathrm{XX})$ must always be two characters in length; for Field 5, for example, 05 must be typed. The specific code within a field (ZZ) may be one to four characters long. Using the above example, if sex is Field 4 and only males are to be counted, input $04 \mathrm{EQM}$, which tells the computer to select only those records in Field 4 which contain an M. If desired, two selections may be made on one tabulation, and a record must pass both conditions to be accepted (selected).

Record Search Features. This special feature allows the user to examine specific records within the data file. For example, suppose in a tabulation of sex by pathology the table printout shows one $G$ in Field 4 which should be either an $\mathrm{M}$ or $\mathrm{F}$ only. The computer can then be directed to search for that $G$ and print the entire record to permit examination for errors. This can be accomplished by typing a " $D$ " as the first character in the selection option (DXXYYZZ). Using the above example for clarification when the selection is requested, D04EQG is input.

As before, two search selections are allowed if de- sired. For example, the above record could also have been located by inputting D04NEM and D04NEF. This not only locates the $G$ in Field 4 , but also locates any other records with an error in Field 4 , that is, not equal to male or female. This works for one or two legitimate fields; other errors are usually selected with "EQ" feature.

Figure 1 provides another example of this detail record select and print feature.

Hardware and Software. This program runs on commonly available Digital Equipment Corporation PDP 8/E computers with one TD8E DECtape. With the use of only one DECtape, program running time is quite slow. For example, on a 1,000-record file with 38 fields, each complete tabulation takes about $15 \mathrm{~min}$. However, this program has been designed to run without user intervention once all information has been input (automated input feature). This permits the user to leave the computer room and spend his time elsewhere, while the runs are being executed and tables printed. The program is currently within about 100 words of core limits.

The PDP $8 / \mathrm{E}$ has a $12 \mathrm{~K}$ core, uses the OS/8 operating system, and uses BASIC as a language. This program is not device dependent and can be run without modification on a floppy disk, at considerably faster rates.

Availability. Program tapes or additional information may be obtained at no charge or cost of materials from Ralph Dippner, State University of New York, State College of Optometry, 100 East 24th Street, New York, New York 10010.

\section{APPENDIX A:}

PROGRAM LISTING

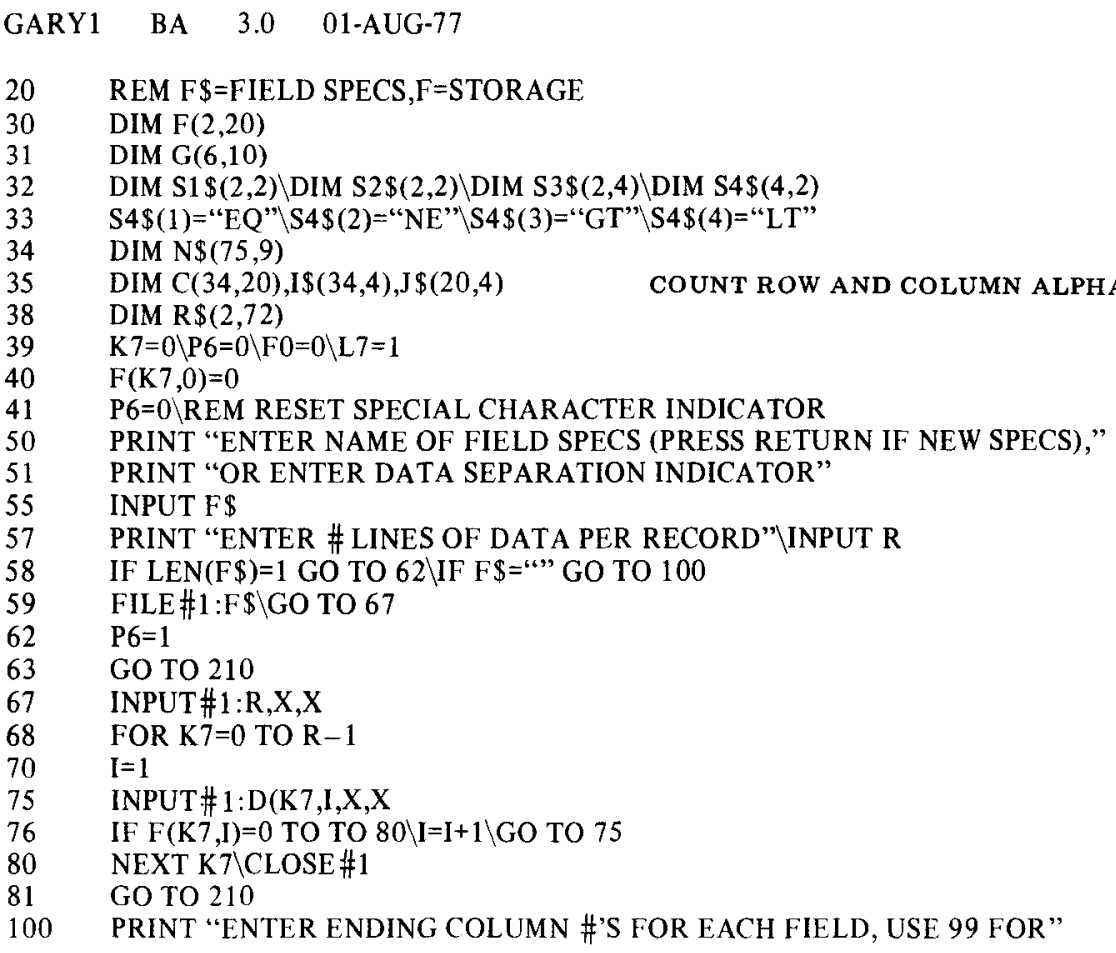


110

120

130

140

180

182

190

194
PRINT "A VARIABLE LAST FIELD, EXTRA RETURN AT END"

$I=I+1$

INPUT $F(K 7, I)$

IF $\mathrm{F}(\mathrm{K} 7, \mathrm{I})=0 \mathrm{GO}$ TO $180 \backslash \mathrm{GO}$ TO 120

PRINT "ENTER NAME FOR FIELD SPEC STORAGE" $\backslash$ INPUT F\$

IF $\mathrm{L} 7<1$ GO TO 200

FILEV\#L $7: F \$$

PRINT\#L7:R

FOR K $7=0$ TO R -1

FOR J=1 TO I $\backslash$ PRINT \#L 7:F(K7,J) \NEXT J \NEXT K7

IF $L 7<1$ TO TO $210 \backslash C L O S E \# L 7$

REM G $\$=$ GROUPING SPECS,G=STORAGE

PRINT "ENTER NAME OF GROUP SPECIFICATION FILE, PRESS RETURN"

PRINT "IF NEW GROUPINGS, ENTER 0 IF NO GROUPINGS"

INPUT G\$IF G\$=“" GO TO 260\IF G\$="0" GO TO 457 $\backslash$ FILE\#1:G\$

REM READ GROUP SPECS

INPUT \# 1: J1,X,X

FOR $L=1$ TO J 1

FOR $M=0$ TO 10

INPUT\# $1: G(L, M), X, X$

IF $G(L, M)=0$ GO TO $247 \backslash$ NEXT M

INPUT \# $1: K(L), X, X$

NEXT L

CLOSE\# $1 \backslash$ GO TO 457

REM CREATE GROUP FILE

FOR J=1 TO 6

PRINT "ENTER FIELD \#TO BE GROUPED, THEN ENTER UPPER BOUNDARY"

PRINT "OF EACH GROUP, PRESS EXTRA RETURN CARRIAGE FOR LAST GROUP"

INPUT $G(J, 0)$

FOR K=l TO 10

INPUT $G(J, K) \backslash$ IF $G(J, K)=0$ GO TO 340

NEXT K

PRINT "MORE GROUPS? IF SO, ENTER A 1."

$K(J)=K-1$

INPUT J6

IF $\mathrm{J} 6<>1$ GO TO 390

NEXT J

PRINT "ENTER NAME FOR GROUP SPEC FILE"

$\mathrm{J} 1=\mathrm{J}$

INPUT G\$

IF $\mathrm{L} 7<1$ GO TO 415

FILEV\#7:G\$

PRINT\# 7:J1\REM STORAGE OF \#OF GROUPS

REM STORAGE OF GROUP SPECS

FOR L $=1$ TO $\mathrm{J} 1$

FOR $M=0$ TO 10

PRINT\#L 7:G(L,M $) \backslash I F ~ G(L, M)=0$ GO TO 455

NEXT M

PRINT\#L 7:K(L)

NEXT L $\backslash$ IF $L 7<1$ GO TO 457\CLOSE \#L7

PRINT "ENTER HEADER FILE NAME, PRESS RETURN TO CREATE NEW HEADERS,"

PRINT "ENTER ZERO FOR NO HEADERS"

INPUT N\$IF N\$="0" GO TO $472 \backslash$ IF N\$="" GO TO 464

FILE\#1:N\$INPUT\#1:F1,X

FOR I=I TO F1 INPUT\# I:N\$(I),X\NEXT I

CLOSE\#1\GO TO 472

PRINT "ENTER \#OF FIELDS PER RECORD"

INPUT F1

PRINT "ENTER NAME OF FIELD"

FOR I=1 TO FI\INPUT N\$(I)\NEXT I

PRINT "ENTER NAME FOR HEADER FILE"

INPUT N\$ $\backslash$ ILEV\#1:N\$ $\$ PRINT\#1:F1

FOR I=1 TO FI\PRINT \# $1: N \$(I) \backslash N E X T$ I $\backslash$ CLOSE\# 1

PRINT "ENTER NAME OF AUTOMATED FIELD INPUT FILE, PRESS RETURN"

PRINT "IF NO AUTOMATION DESIRED"

INPUT YS $\backslash$ IF LEN(Y $\$=0$ GO TO $475 \backslash F 0=2 \backslash F I L E \# 2: Y \$$

PRINT “ENTER DATA FILE NAME”

INPUT DS

FILE\#1:D\$

REM ZERO TABLES

FOR I=0 TO I9

LINES 480-1000 SELECT THE RECORD 
500

510

520

530

540

599

600

610

620

621

640

645

655

660

661

662

663

665

667

670

680

690

700

710

720

829

830

837

838

840

841

842

843

844

845

846

847

848

849

850

880

881

895

898

900

905

915

917

918

919

920

925

930

935

940

945

950

960

990

991

992

994

1000

1002

1004

1006

1008

1013

1014

1015

1018
FOR $J=0$ TO J9

$\mathrm{C}(\mathrm{I}, \mathrm{J})=0$

NEXT J

NEXT I

$\mathrm{I} 9=0 \backslash \mathrm{J} 9=0$

$F=0 \backslash$ PRINT

PRINT "WHAT FIELDS AND \%'S? USE THE FORM X,Y,P"

INPUT \#F0:X,Y,P

IF F0 $=0$ GO TO 640\IF END\#2 GO TO 9985 INPUT\#2:XI

PRINT X;",";Y;",";P

REM SELECTION

R $3=0$

PRINT "SELECTION IF ANY, PRESS RETURN IF NO SELECTION"

INPUT\#F0:S\$

IF F0=0 GO TO $663 \backslash$ INPUT \#2:X1

PRINT S\$

IF $S \$=$ "" GO TO 829

IF SEG $\$(\$ \$, 1,1)<>$ “D” GO TO 670

$S \$=S E G \$(S \$, 2, \mathrm{LEN}(\mathrm{S} \$)) \backslash \mathrm{F}=1$

LINES 667 and 991-994

ALLOW GARBAGE CLEAN OUT

MAKE YOUR 1ST REPORT A WORST CASE

$\mathrm{S} 1 \$(\mathrm{R} 3)=\mathrm{SEG} \$(\mathrm{~S} \$, 1,2) \backslash \mathrm{S} 2 \$(\mathrm{R} 3)=\mathrm{SEG} \$(\mathrm{~S} \$, 3,4) \backslash \mathrm{S} 3 \$(\mathrm{R} 3)=\mathrm{SEG} \$(\mathrm{~S} \$, 5, \mathrm{LEN}(\mathrm{S} \$))$

FOR I4=1 TO 4\IF S2\$(R3)=\$4\$(I4) GO TO 690 \NEXT I4

$I 5(R 3)=I 4$

$\mathrm{R} 3=\mathrm{R} 3+1$

IF R $3=2$ GO TO 829

PRINT “ANOTHER";) GO TO 655

$\mathrm{Z}=0 \backslash$ REM READ FIRST RECORD

FOR K $7=0$ TO R -1

INPUT \#1:R\$(K7)\IF END\#1 GO TO 1200

NEXT K7

IF $P 6=0$ GO TO 850

IF $\mathrm{Z}>0$ GO TO 850

$\mathrm{Z}=\mathrm{Z}+1$

FOR $K 7=0$ TOR $-1 \backslash C 4(K 7)=1$

FOR C5 $=1$ TO LEN $(R \$(K 7))-1$

IF SEG $\$(R \$(K 7), C 5, C 5)<>F \$$ GO TO 847

$\mathrm{C} 4(\mathrm{~K} 7)=\mathrm{C} 4(\mathrm{~K} 7)+1$

NEXT C $5 \backslash$ NEXT K 7

FOR K $7=1$ TO $\mathrm{R}-1 \backslash \mathrm{C} 4(\mathrm{~K} 7)=\mathrm{C} 4(\mathrm{~K} 7)+\mathrm{C} 4(\mathrm{~K} 7-1) \backslash \mathrm{NEXT} \mathrm{K}$ ?

REM C4(K7)= \#OF FIELDS IN LINE \#K7 OF RECORD R\$(K7)

FOR R4=0 TO R3-1

$\mathrm{J}=\mathrm{VAL}(\mathrm{S} 1 \$(\mathrm{R} 4))$

IF P6=0 GO TO 915

FOR K $7=0$ TO $R-1$

IF J $>$ C4(K7) GO TO 900\GO TO 905

NEXT K7 $\backslash$ RESTORE\# $\backslash \backslash$ GO TO 600

F9=J $\backslash$ GOSUB 5000 $\backslash$ GO TO 920

$\mathrm{K} 7=0$

$\mathrm{H} \$=\mathrm{SEG} \$(\mathrm{R} \$(\mathrm{~K} 7), \mathrm{F}(\mathrm{K} 7, \mathrm{~J}-1, \mathrm{~F}(\mathrm{~K} 7, \mathrm{~J}))$

$\mathrm{X} \$=\mathrm{H} \$ \mathrm{~F} 9=\mathrm{J} \backslash \mathrm{GOSUB} 7000$

IF $\mathrm{D}<>1$ GO TO $920 \backslash \mathrm{H} \$=\mathrm{STR} \$(\mathrm{~K}) \backslash \mathrm{D}=0$

IF I5(R4)>1 GO TO 930

IF $\mathrm{H} \$=\$ 3 \$(\mathrm{R} 4)$ GO TO $990 \backslash \mathrm{GO}$ TO 830

IF I5(R4)>2 GO TO 940

IF H\$<>S3\$(F4) GO TO $990 \backslash$ GO TO 830

IF I5(R 4$)>3$ GO TO 950

IF H\$>S3\$(R4) GO TO $990 \backslash$ GO TO 830

IF $\mathrm{H} \$<$ S3\$(R4) GO TO 990

GO TO 830

NEXT R4

IF $F<>1$ GO TO 1002

FOR K $7=0$ TO R-1 \PRINT R $\$(K 7) \backslash N E X T$ K 7

GO TO 830

REM RECORD IS SELECTED IF WE GET HERE

IF P $6=0$ GO TO 1020

FOR K7=0 TO R-1 \IF X>C4(K7) GO TO $1006 \backslash G O$ TO 1008

NEXT K $7 \backslash$ RESTORE \# $1 \backslash$ GO TO 600

F9=X $\backslash$ GOSUB $5000 \backslash I \$=H \$$

FOR K7=0 TO R -1 \IF $Y>C 4(K 7)$ GO TO $1014 \backslash G O$ TO 1015

NEXT K $7 \backslash$ RESTORE\# $1 \backslash$ GO TO 600

$\mathrm{F} 9=\mathrm{Y} \backslash \mathrm{GOSUB} 500 \backslash \mathrm{J} \$=\mathrm{H} \$$

GO TO 1040 


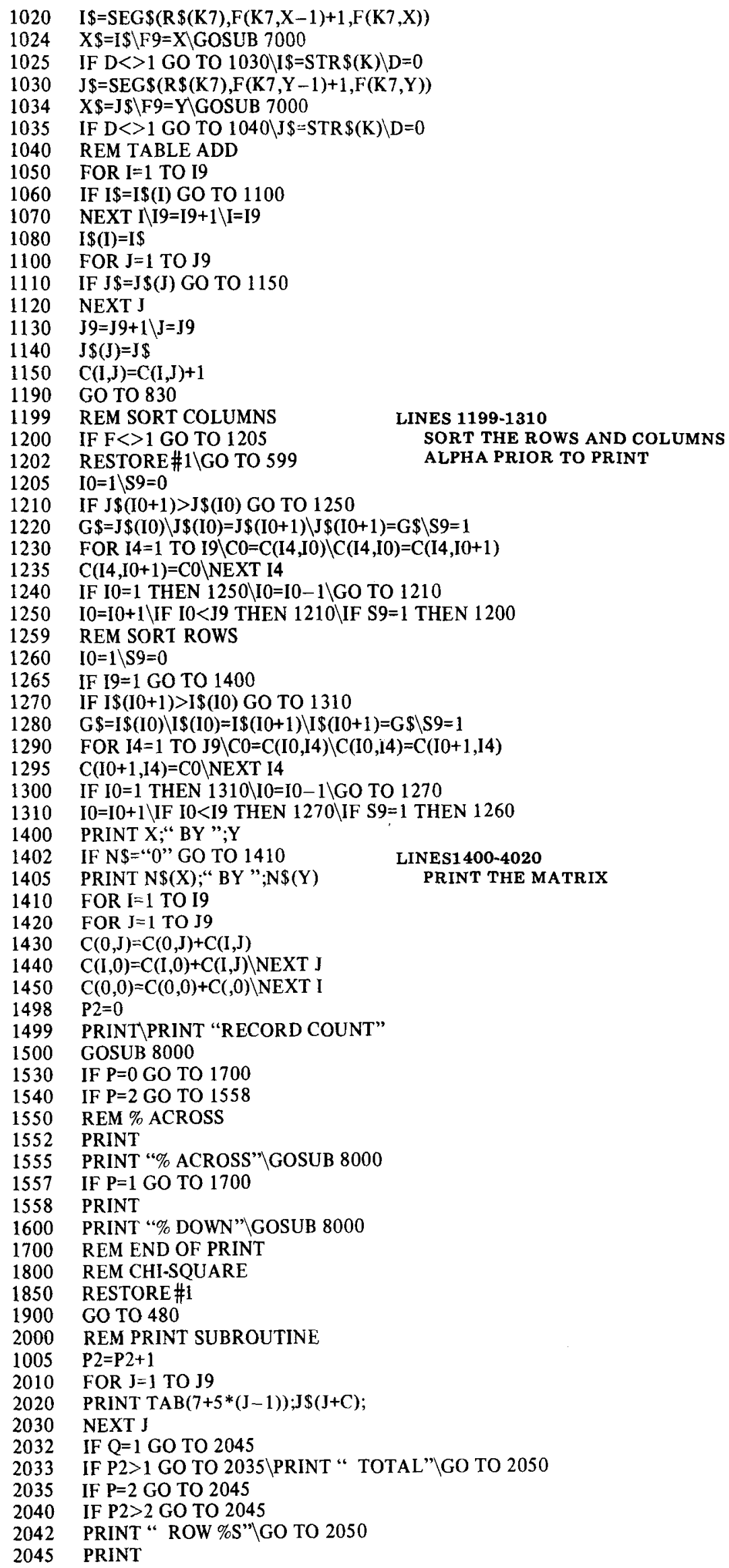


2050

2060

2070

2080

2090

2091

2092

2095

3001

3002

3005

3010

3015

3016

3017

3018

3020

3025

3026

3030

3040

3041

3042

3050

3060

4000

4005

4010

4015

4020

5000

5002

5004

5006

5008

5010

5020

5025

5030

5040

5050

5060

5070

5080

5090

6000

6001

6002

6003

7000

7010

7020

7030

7035

7040

7050

7060

8000

8010

8020

8030

8040

9985

9990

9999

FOR $\mathbf{I}=1$ TO I9

PRINT I\$(I);

FOR $J=1$ TO J9

PRINT TAB $(6+5 *(\mathrm{~J}-1)) ;$ GOSUB 4000

NEXT J

IF $\mathrm{Q}=1 \mathrm{GO}$ TO 3005

IF P2>1 TO TO 3001 \PRINT TAB $(6+5 * \mathrm{~J} 9) ; \mathrm{C}(\mathrm{I}, 0)$

GO TO 3010

IF P2=3 GO TO $3005 \backslash$ IF $\mathrm{P}=2$ GO TO 3005

PRINT TAB $(6+5 * \mathrm{~J} 9) ; \mathrm{INT}(\mathrm{C}(\mathrm{I}, 0) / \mathrm{C}(0,0) * 100+.5)$;

PRINT

NEXT I

IF P2=3 GO TO 3018

IF $P 2=1$ GO TO 3020

IF $\mathrm{P}=2$ GO TO $3018 \backslash \mathrm{GO}$ TO 3050

PRINT "COL \%S";

FOR J $=1$ TO J9

IF P2=1 GO TO 3030

PRINT TAB $(6+5 *(\mathrm{~J}-1)) ; \operatorname{INT}(\mathrm{C}(0, \mathrm{~J}+\mathrm{C}) / \mathrm{C}(0,0) * 100+.5) ; \mathrm{GO}$ TO 3040

PRINT TAB $(6+5 *(\mathrm{~J}-1)) ; \mathrm{C}(0, \mathrm{~J}+\mathrm{C})$;

NEXT J

IF $\mathrm{Q}=1$ GO TO 3060

IF P2>1 GO TO 3060\PRINT TAB $(6+5 * J 9) ; C(0,0)$

PRINT\RETURN

PRINT \PRINT \RETURN

IF P2>1 GO TO 4005 $\backslash$ PRINT C (I,J+C); $\backslash$ RETURN

IF $P=2$ GO TO 4020

IF P2>2 GO TO 4020

PRINT INT $(\mathrm{C}(1, \mathrm{~J}+\mathrm{C}) / \mathrm{C}(\mathrm{I}, 0) * 100+.5) ; \backslash \mathrm{RETURN}$

PRINT INT $(\mathrm{C}(\mathrm{I}, \mathrm{J}+\mathrm{C}) / \mathrm{C}(0, \mathrm{~J}+\mathrm{C}) * 100+.5) ;$ RETURN

$\mathrm{F} 8=\mathrm{F} 9 \backslash \mathrm{C} 6(\mathrm{~K} 7)=\mathrm{C} 4(\mathrm{~K} 7)$

IF K $7=0$ GO TO 5008

$\mathrm{F} 8=\mathrm{F} 9-\mathrm{C} 4(\mathrm{~K} 7-1)$

LINES 5000-6003

$\mathrm{C} 6(\mathrm{~K} 7)=\mathrm{C} 4(\mathrm{~K} 7)-\mathrm{C} 4(\mathrm{~K} 7-1)$

ISOLATE A FIELD

$\mathrm{P} 5=0 \backslash \mathrm{P} 4=0$

P5 $=$ P5+1 $\backslash$ IF SEG $\$(R \$(K 7), P 5, P 5)=F \$$ GO TO $5020 \backslash$ GO TO 5010

$\mathrm{P} 4=\mathrm{P} 4+1$

IF $\mathrm{P} 4=\mathrm{F} 8 \mathrm{GO}$ TO 6000

IF P4=F8-1 GO TO 5040 \GO TO 5010

$\mathrm{P} 4=\mathrm{P} 5+1$

IF F8=C6(K7) GO TO 5090

FOR P5 $=$ P4+1 TO LEN(R\$(K7))

IF SEG $\$(\mathrm{R} \$(\mathrm{~K} 7), \mathrm{P} 5, \mathrm{P} 5)=\mathrm{F} \$$ GO TO 6000

NEXT P5

P5 $=\operatorname{LEN}(\mathrm{R} \$(\mathrm{~K} 7))+1$

$\mathrm{H} \$=\mathrm{SEG} \$(\mathrm{R} \$(\mathrm{~K} 7), \mathrm{P} 4, \mathrm{P} 5-1$

$X \$=H \$ \backslash G O S U B 7000$

IF $\mathrm{D}<>1$ GO TO $6003 \backslash \mathrm{H} \$=\mathrm{STR} \$(\mathrm{~K}) \backslash \mathrm{D}=0$

RETURN

REM GROUPING SUBROUTINE

FOR $\mathbf{J}=1$ TO $\mathbf{J} 1$

IF $F 9=G(J, 0)$ GO TO 7035

LINES 7000-7060

NEXT J $\backslash$ RETURN

$\mathrm{D}=1$

FOR $\mathrm{K}=1$ TO $\mathrm{K}(\mathrm{J})$

IF VAL(X\$)<=G(J,K) GO TO 7060\NEXT K

RETURN

$\mathrm{C}=0$

IF J9>10 GO TO 8030

LINES 8000-8040

GOSUB 2000\RETURN

ALLOW PRINTING OF MATRICES OF

$\mathrm{J} 8=\mathrm{J} 9 \backslash \mathrm{J} 9=10 \backslash \mathrm{Q}=1 \backslash \mathrm{GOSUB} 2000$

$\mathrm{Q}=0 \backslash \mathrm{C}=10 \backslash \mathrm{J} 9=\mathrm{J} 8-10 \backslash \mathrm{P} 2=\mathrm{P} 2-1 \backslash \mathrm{GOSUB} 2000 \backslash \mathrm{J} 9=\mathrm{J} 8 \backslash \mathrm{RETURN}$

PRINT "END OF PRINT"

STOP

END

READY 
NOTE TO PROGRAM MODIFIERS: THIS PROGRAM IS WITHIN ABOUT 100 LOCATIONS OF FILLING USABLE CORE. DIMENSION STATEMENTS MUST BE CUT OR CODING DELETED IF ANY ADDITIONS TO THE PROGRAM (E.G., CHI-SQUARE) ARE TO BE MADE.

\section{NOTE}

1. See TECO, Chapter 2 of OS/8 Handbook, Digital Equipment Corporation, Maynard, Massachusetts, April 1974.

(Received for publication September 20, 1977; revision accepted November 15, 1977.) 